\title{
PENGARUH JENIS MULSA DAN DOSIS KOMPOS TERHADAP HASIL PANEN CABAI RAWIT (Capsicum frutescens $\mathbf{L}$.)
}

\section{THE EFFECT OF MULCH TYPE AND COMPOST DOSAGE ON CAYENNE PEPPER (Capsicum frutescens L.) HARVEST YIELD}

\author{
Ahmad Raksun, Mahrus dan I Gde Mertha \\ Dosen Program Studi Pendidikan Biologi FKIP UNRAM \\ Email: ahmadunram@unram.ac.id
}

Diterima: 8 Oktober 2019. Disetujui: 8 Oktober 2019. Dipublikasikan: 9 Januari 2020

\begin{abstract}
Abstrak: Penelitian tentang pengaruh jenis mulsa dan dosis kompos terhadap hasil panen cabai rawit, telah dilaksanakan di Desa Bajur Kabupaten Lombok Barat. Tujuan penelitian ini adalah untuk mengetahui: (1) pengaruh jenis mulsa terhadap hasil panen cabai rawit, (2) pengaruh dosis kompos terhadap hasil panen cabai rawit, (3) pengaruh interaksi antara jenis mulsa dan dosis kompos terhadap hasil panen cabai rawit. Dalam penelitian ini digunakan rancangan faktorial yang terdiri atas 2 faktor. Faktor pertama adalah jenis mulsa yang terdiri atas 3 macam mulsa yaitu mulsa plastik hitam perak $\left(\mathrm{M}_{1}\right)$, mulsa jerami padi $\left(\mathrm{M}_{2}\right)$ dan mulsa daun-daun kering $\left(\mathrm{M}_{3}\right)$. Faktor kedua adalah dosis kompos yang terdiri atas 6 level yaitu: $\mathrm{K}_{\mathrm{o}}=$ tampa pemberian kompos, $\mathrm{K}_{1}=$ pemberian 0,4 kg kompos $/ 1 \mathrm{~m}^{2}$ lahan, $\mathrm{K}_{2}=$ pemberian $0,8 \mathrm{~kg}$ kompos $/ 1 \mathrm{~m}^{2}$ lahan, $\mathrm{K}_{3}=$ pemberian $1,2 \mathrm{~kg}$ kompos $/ 1 \mathrm{~m}^{2}$ lahan, $\mathrm{K}_{4}=$ pemberian $1,6 \mathrm{~kg}$ kompos $/ 1 \mathrm{~m}^{2}$ lahan, $\mathrm{K}_{5}=$ pemberian $2,0 \mathrm{~kg}$ kompos $/ 1 \mathrm{~m}^{2}$ lahan. Parameter hasil panen yang diukur adalah panjang buah dan berat basah buah cabai rawit. Analisis data dilakukan dengan analisis sidik ragam. Hasil penelitian menunjukkan bahwa: (1) perbedaan jenis mulsa berpengaruh sangat nyata terhadap panjang buah dan berat basah buah cabai rawit, mulsa plastik hitam perak menghasilkan panjang dan berat basah buah cabai rawit lebih tinggi dari pada mulsa lainnya, (2) dosis kompos berpengaruh sangat nyata terhadap panjang buah dan berat basah buah cabai rawit, dosis kompos optimum adalah 1,6 - $2 \mathrm{~kg}$ kompos per $1 \mathrm{~m}^{2}$ lahan, (3) interaksi jenis mulsa dan dosis kompos tidak berpengaruh nyata terhadap panjang buah dan berat basah buah cabai rawit.
\end{abstract}

Kata-kata kunci: mulsa, kompos, hasil panen cabai rawit

Abtarct: Research on the effect of mulch types and compost doses on chili yields has been carried out in Bajur Village, West Lombok Regency. The purpose of this study was to determine: (1) the effect of mulch type on the yield chili, (2) the effect of compost dose on the yield of chili, (3) the effect of the interaction between the types of mulch and compost doses on the yield of chili. In this study used a factorial design consisting of 2 factors. The first factor is the type of mulch which consists of 3 types of mulch namely black silver plastic mulch $\left(\mathrm{M}_{1}\right)$, rice straw mulch $\left(\mathrm{M}_{2}\right)$ and dry leaf mulch $\left(\mathrm{M}_{3}\right)$. The second factor is the compost dose which consists of 6 levels, namely: $\mathrm{Ko}=$ without giving compost, $\mathrm{K}_{1}=$ giving $0.4 \mathrm{~kg}$ of compost $/ 1 \mathrm{~m}^{2}$ of land, $\mathrm{K}_{2}=$ giving $0.8 \mathrm{~kg}$ of compost $/ 1 \mathrm{~m}^{2}$ of land, $\mathrm{K}_{3}=$ giving $1.2 \mathrm{~kg}$ of compost $/ 1 \mathrm{~m}^{2}$ of land, $\mathrm{K}_{4}=$ giving $1.6 \mathrm{~kg}$ of compost $/ 1 \mathrm{~m}^{2}$ of land, $\mathrm{K}_{5}=$ giving $2.0 \mathrm{~kg}$ of compost $/ 1 \mathrm{~m}^{2}$ of land. The yield parameters measured were fruit length and wet weight of chili. Data analysis was performed by analysis of variance. The results showed that: (1) different types of mulch have a very significant effect on fruit length and wet weight of chili, silver black plastic mulch produces a length and wet weight of chili fruit is higher than other mulches, (2) compost dose has a very significant effect on fruit length and wet weight of chili, the optimum compost dose is $1.6-2 \mathrm{~kg}$ of compost per $1 \mathrm{~m} 2$ of land, (3) the interaction of mulch type and compost dose does not significantly affect the length and wet weight of chili fruit

Keywords: mulch, compost, yield of chili

\section{PENDAHULUAN}

Ketersediaan unsur hara pada media tanamam merupakan salah satu faktor yang sangat menentukan terhadap pertumbuhan dan hasil panen tanaman. Upaya meningkatkan ketersediaan unsur hara dapat dilakukan dengan pemberian kompos pada media tanam. Hasil penelitian yang dilakukan oleh [14] menunjukkan bahwa pemberian kompos pada media tanam berpengaruh terhadap diameter batang dan jumlah daun tanaman lidah buaya. Pertumbuhan tanaman cukup baik pada pemberian dosis sekitar $150 \mathrm{~g}$ per pot. [11] menyimpulkan bahwa aplikasi kompos pada lahan pertanian Desa Montong berpengaruh signifikan terhadap hasil panen tomat. Kadar optimum kompos yang perlu diberikan pada lahan pertanian Desa Montong Are agar tomat berproduksi secara optimal adalah $1,2 \mathrm{~kg}$ untuk setiap $10 \mathrm{~kg}$ tanah. [1] Demikian juga [1] menyimpulkan bahwa pemberian kompos greenbotane pada bibit kelapa sawit berpengaruh nyata terhadap parameter tinggi tanaman, diameter 
bonggol, berat basah, berat kering bibit dan rasio tajuk akar. Peningkatan dosis perlakuan didiringi dengan peningkatan pertumbuhan bibit di setiap parameter pengamatan. Pemberian pupuk kompos greenbotane dosis $200 \mathrm{~g} /$ polybag merupakan dosis perlakuan terbaik terhadap seluruh parameter pengamatan.

Selain penggunaan pupuk kompos, penggunaan mulsa juga berpengaruh terhadap pertumbuhan dan hasil panen tanaman. Mulsa adalah bahan atau material yang digunakan untuk menutupi permukaan tanah atau lahan pertanian. [7] menjelaskan bahwa penggunaan mulsa dapat memberikan keuntungan antara lain menghemat penggunaan air dengan mengurangi laju evaporasi dari permukaan lahan, memperkecil fluktuasi suhu tanah sehingga menguntungkan pertumbuhan akar dan mikroorganisme tanah, memperkecil laju erosi tanah baik akibat tumbukan butir-butir hujan maupun aliran permukaan dan menghambat pertumbuhan gulma.

Berdasarkan uraian di atas maka peneliti melakukan penelitian tentang pengaruh jenis mulsa dan dosis kompos terhadap hasil panen tanaman cabai rawit yang dilakukan di Desa Bajur Kecamatan Labuapi Kabupaten Lombok Barat. Adapun tujuan dilaksanakannya penelitian ini adalah untuk mengetahui: (1) pengaruh jenis mulsa terhadap hasil panen cabai rawit (2) pengaruh dosis kompos terhadap hasil panen cabai rawit, (2) pengaruh interaksi jenis mulsa dan dosis kompos terhadap hasil panen cabai rawit.

\section{BAHAN DAN METODE}

Bahan-bahan yang digunakan adalah kotoran kuda, dedak halus, sekam, benih cabai rawit, kawat, tanah sawah, insektisida, fungisida dan air. Selanjutnya alat-alat yang digunakan adalah ember plastik, terpal, cangkul, linggis, karung goni, karung nilon, parang, sekop, sendok, dan gelas ukur. Penelitian dilakukan dengan tahapan-tahapan: (1) pembuatan kompos dengan bahan baku kotoran kuda, sekam dan dedak, (2) melakukan pembibitan cabai rawit varietas taruna dengan media tanah menggunakan pot palstik, (3) mengolah lahan pertanian dan membuat bedengan, (4) aplikasi kompos pada bedengan lahan sesuai dosis perlakuan, (5) menutup bedengan menggunakan mulsa palstik hitam perak, mulsa jerami padi dan mulsa daun daun kering, (6) penanaman dan pemeliharaan cabai rawit, (7) pengukuran parameter hasil panen cabai rawit.

Dalam penelitian ini digunakan rancangan faktorial yang terdiri atas 2 faktor. Faktor pertama adalah jenis mulsa yang terdiri atas 3 macam mulsa yaitu: $\mathbf{M}_{1}=$ mulsa plastik hitam perak, $\mathbf{M}_{2}=$ mulsa jerami padi dan $\mathbf{M}_{3}=$ mulsa daun-daun kering. Faktor kedua adalah dosis kompos yang terdiri atas 6 aras yaitu: $\mathrm{K}_{\mathrm{o}}=$ tampa pemberian pupuk kompos, $\mathrm{K}_{1}=$ pemberian $0,4 \mathrm{~kg}$ kompos per $1 \mathrm{~m}^{2}$ lahan, $\mathrm{K}_{2}$ $=$ pemberian $0,8 \mathrm{~kg}$ kompos per $1 \mathrm{~m}^{2}$ lahan, $\mathrm{K}_{3}=$ pemberian $1,2 \mathrm{~kg}$ kompos per $1 \mathrm{~m}^{2}$ lahan, $\mathrm{K}_{4}=$ pemberian $1,6 \mathrm{~kg}$ kompos per $1 \mathrm{~m}^{2}$ lahan, $\mathrm{K}_{5}=$ pemberian $2,0 \mathrm{~kg}$ kompos per $1 \mathrm{~m}^{2}$ lahan. Semua kombinasi perlakuan dilakukan dengan 3 ulangan sehingga diperoleh $3 \times 6 \times 3=54$ unit percobaan.

Penelitian dilaksanakan di Desa Bajur Kecamatan Labuapi Kabupaten Lombok Barat Propinsi Nusa Tenggara Barat. Pertama-tama lahan pertanian dibersihkan dari rumput dan sisasisa tanaman dan tanah dibongkar menggunakan cangkul. Selanjutnya dibuat bedengan lahan dengan ukuran lebar $85 \mathrm{~cm}$ dan panjang 9 meter. Aplikasi kompos dilakukan 32 hari sebelum tanam sesuai dosis perlakuan. Pemasangan mulsa dilakukan 4 hari sebelum tanam. Parameter hasil panen yang diukur adalah panjang buah dan berat basah buah. Data kuantitatif hasi pengukuran parameter, dianalisis dengan analisis sidik ragam dan uji lanjut dengan Uji Beda Nyata Terkecil [3]

\section{HASIL PENELITIAN DAN PEMBAHASAN}

Percobaan tentang pengaruh jenis mulsa dan dosis kompos terhadap hasil panen cabai rawit telah dilaksanakan di Desa Bajur Kecanatan Labuapi Kabupaten Lombok Barat Propinsi Nusa Tenggara Barat. Data hasil pengukuran panjang buah cabai rawit terdapat pada tabel 1 .

Tabel 1. Rerat Panjang Buah Cabai Rawit, akibat Perbedaan Jenis Mulsa dan Dosis Kompos.

\begin{tabular}{ccccccc}
\hline Perlakuan & $\mathbf{K}_{\mathbf{0}}$ & $\mathbf{K}_{\mathbf{1}}$ & $\mathbf{K}_{\mathbf{2}}$ & $\mathbf{K}_{\mathbf{3}}$ & $\mathbf{K}_{\mathbf{4}}$ & $\mathbf{K}_{\mathbf{5}}$ \\
\hline $\mathbf{M}_{\mathbf{1}}$ & 35 & 38 & 41 & 45 & 47 & 48 \\
$\mathbf{M}_{\mathbf{2}}$ & 31 & 35 & 38 & 41 & 43 & 45 \\
$\mathbf{M}_{\mathbf{3}}$ & 30 & 32 & 35 & 37 & 39 & 40 \\
\hline
\end{tabular}

Data pada tabel 1. menunjukkan bahwa rerata panjang buah cabai rawit tertinggi adalah $48 \mathrm{~mm}$, terdapat pada perlakuan $\mathrm{M}_{1} \mathrm{~K}_{5}$ (cabai rawit yang ditanam pada lahan yang diberikan mulsa plastik hitam perak dan kompos dengan dosis $2 \mathrm{~kg}$ per 1 $\mathrm{m}^{2}$ lahan pertanian). Panjang cabai rawit terendah terdapat pada perlakuan $\mathrm{M}_{3} \mathrm{~K}_{0}$ (cabai rawit yang ditanam pada lahan yang diberikan mulsa daundaun kering dan tidak diberikan kompos). Hasil analisis sidik ragam terdapat pada tabel 2 .

Hasil analisis sidik ragam menunjukkan bahwa perbedaan jenis mulsa berpengaruh sangat nyata terhadap panjang buah cabai rawit. 
Perbedaan dosis kompos berpengaruh sangat nyata terhadap panjang buah cabai rawit. Interaksi antara jenis mulsa dan dosis kompos tidak berpengaruh nyata terhadap panjang buah cabai rawit. Selanjutnya data hasil pengukuran berat basah buah cabai rawit terdapat pada tabel 3.

Data pada tabel 3. Menunjukkan bahwa berat basah cabai rawit terendah adalah 239 gram, terdapat pada perlakuan $\mathrm{M}_{3} \mathrm{~K}_{0}$ (lahan yang diberikan mulsa daun-daun kering dan tidak diberikan kompos). Berat buah cabai rawit tertinggi adalah 276 gram, terdapat pada perlakuan $\mathrm{M}_{1} \mathrm{~K}_{5}$ (lahan yang diberikan mulsa plastik hitam perak dan $2 \mathrm{~kg}$ kompos per $1 \mathrm{~m}^{2}$ lahan pertanian). Hasil analisis sidik ragam pengaruh jenis mulsa dan dosis kompos terhadap berat basah buah cabai rawit terdapat pada tabel 4 .

Tabel 2. Hasil Analisis Sidik Ragam Pengaruh Jenis Mulsa dan Dosis Kompos terhadap Panjang Buah Cabai Rawit

\begin{tabular}{lcccccc}
\hline \multicolumn{1}{c}{ Sumber keragaman } & DB & JK & KT & F. Hitung & $5 \%$ & $1 \%$ \\
\hline Ulangan & 2 & 0,1 & 0,05 & & & F tabel \\
Perlakuan & 17 & 1469,3 & 86,43 & & & 5,29 \\
Mulsa (M) & 2 & 420,3 & 210,15 & $34,70^{* *}$ & 3,28 & 3,61 \\
Kompos (K) & 5 & 1029,3 & 205,86 & $33,99^{* *}$ & 2,49 & 2,89 \\
M x K & 10 & 19,7 & 1,97 & $0,33^{\text {NS }}$ & 2,12 & \\
Galat & 34 & 205,9 & 6,06 & & & \\
Umum & 53 & 1675,3 & 31,61 & & & \\
\hline
\end{tabular}

Tabel 3. Rerata Berat Basah Buah Cabai Rawit (gram) akibat Perbedaan Jenis Mulsa dan Dosis Kompos.

\begin{tabular}{crrrrcr}
\hline Perlakuan & B $_{\mathbf{0}}$ & $\mathbf{B}_{\mathbf{1}}$ & $\mathbf{B}_{\mathbf{2}}$ & $\mathbf{B}_{\mathbf{3}}$ & $\mathbf{B}_{\mathbf{4}}$ & $\mathbf{B}_{\mathbf{5}}$ \\
\hline $\mathbf{M}_{1}$ & 254 & 259 & 263 & 270 & 275 & 276 \\
$\mathbf{M}_{2}$ & 242 & 246 & 252 & 258 & 264 & 263 \\
$\mathbf{M}_{3}$ & 239 & 243 & 245 & 257 & 263 & 264 \\
\hline
\end{tabular}

Tabel 4. Hasil Analisis Sidik Ragam Pengaruh Jenis Mulsa dan Dosis Kompos terhadap Berat Basah Buah Cabai Rawit

\begin{tabular}{lcccccc}
\hline \multicolumn{1}{c}{ Sumber keragaman } & DB & JK & KT & F. Hitung & $5 \%$ & $1 \%$ \\
\hline Ulangan & 2 & 3,28 & 1,64 & & & \\
Perlakuan & 17 & 6319 & 371,71 & & & \\
Mulsa (M) & 2 & 2129,5 & 1064,75 & $71,28^{* *}$ & 3,28 & 5,29 \\
Kompos (K) & 5 & 4119 & 823,80 & $55,15^{* *}$ & 2,49 & 3,61 \\
M X K & 10 & 70,5 & 7,05 & $0,47^{\text {NS }}$ & 2,12 & 2,89 \\
Galat & 34 & 507,9 & 14,94 & & & \\
Umum & 53 & 6563 & 123,83 & & & \\
\hline
\end{tabular}

Hasil analisis sidik ragam menunjukkan bahwa perbedaan jenis mulsa berpengaruh sangat nyata terhadap berat basah buah cabai rawit. Perbedaan dosis kompos berpengaruh sangat nyata terhadap berat basah buah cabai rawit. Interaksi antara jenis mulsa dan dosis kompos tidak berpengaruh nyata terhadap berat basah buah cabai rawit.

Dalam penelitian ini perbedaan jenis mulsa berpengaruh sangat nyata terhadap panjang buah dan berat basah buah cabai rawit. Panjang buah dan berat basah buah tertinggi terdapat pada cabai rawit yang ditanam pada lahan yang ditutupi mulsa plastik hitam perak. Hasil penelitian ini sejalan dengan hasil penelitian yang dilakukan oleh [8] yang menyimpulkan bahwa penggunaan mulsa plastik hitam perak menghasilkan tanaman bawang merah yang paling tinggi, jumlah daun dan jumlah umbi per rumpun yang paling banyak, serta berat segar umbi per rumpun dan berat umbi kering simpan per rumpun yang paling berat. Pengunaan mulsa pada jarak tanam yang berbeda memberikan respon yang sama pada parameter pengamatan. Demikian juga [10] menyimpulkan bahwa penggunaan mulsa plastik hitam perak dengan bentuk datar tinggi $40 \mathrm{~cm}$ menghasilkan tinggi tanaman lebih tinggi dari tanaman kubis bunga pada perlakuan lainnya

Perbedaan dosis kompos juga berpengaruh sangat nyata terhadap panjang buah dan berat basah buah cabai rawit. Panjang buah dan berat basah buah cabai rawit tertinggi terdapat pada perlakuan dengan dosis kompos $2 \mathrm{~kg}$ per $1 \mathrm{~m}^{2}$ lahan pertanian. Hasil penelitian ini sejalan dengan hasil 
penelitian yang dilakukan oleh [5] yang menyimpulkan bahwa pemberian pupuk kompos mampu meningkatkan pertumbuhan dan produksi padi di lahan pasang surut sulfat masam. [12] menyimpulkan bahwa penggunaan kompos pada lahan pertanian Desa Sukarara berpengaruh nyata terhadap panjang batang dan jumlah anak daun kacang panjang. Dosis optimum kompos yang perlu diberikan pada lahan pertanian Desa Sukarara agar kacang panjang dapat tumbuh secara optimal adalah 2,0 kg kompos untuk $1 \mathrm{~m}^{2}$ lahan pertanian. Selanjutnya pemberian kompos berpengaruh nyata terhadap tinggi tanaman, panjang daun, lebar daun, diameter batang, waktu muncul bunga jantan dan bunga betina, panjang tongkol dan jumlah biji tanaman jagung manis [13]

Demikian juga [2] menyimpulkan bahwa kedelai varietas galunggung merespon secara signifikan terhadap kompos limbah kelapa sawit, produksi meningkat secara sigifikan. Pemberian kompos berpengaruh nyata terhadap tinggi tanaman, umur berbunga, umur panen dan berat buah pertanaman [9]. Pemberian pupuk kompos berpengaruh nyata pada tinggi tanaman sawi umur 16 hari dan 40 hari setelah tanam. Pemberian kompos berpengaruh nyata pada berat berangkasan basah 1 kali panen. Pemberian pupuk kompos berpengaruh nyata terhadap jumlah akar [4]. Penggunaan pupuk organik baik yang berasal dari kompos rami maupun pupuk kandang sapi dapat mengurangi pemakaian pupuk anorganik sebanyak $50 \mathrm{~kg} \mathrm{~N}$ perhektar [6]

\section{KESIMPULAN}

Dalam penelitian ini disimpulkan bahwa: (1) perbedaan jenis mulsa berpengaruh nyata terhadap panjang buah dan berat basah buah cabai rawit, panjang dan berat basah buah tertinggi terdapat pada cabai rawit yang ditanam pada lahan yang ditutupi mulsa plastik hitam perak, (2) dosis kompos berpengaruh nyata terhadap panjang buah dan berat basah buah cabai rawit, dosis kompos optimum adalah 1,6 - $2 \mathrm{~kg}$ kompos per $1 \mathrm{~m}^{2}$ lahan pertanian, (3) interaksi jenis mulsa dan dosis kompos tidak berpengaruh nyata terhadap panjang dan berat basah buah cabai rawit.

\section{DAFTAR PUSTAKA}

[1] Andre, R.K. dan Wawan. 2017. Pengaruh Pemberian Beberapa Dosis Pupuk Kompos (Greenbotane) terhadap Pertumbuhan Bibit Kelapa Sawit (Elaeis quteneensis Jacq) di Pembibitan Utama. JOM Faperta. Vol. 4 (2): $1-14$

[2] Darma,S. 2000. Respon Tanaman Kedelai Terhadap Kompos Limbah Kelapa Sawit pada Dosis Berbeda. Budidaya Pertanian. Vol. 6 (2): 96 - 104
[3] Gomez K.A. dan A.A. Gomez. 1995. Prosedur Statistik Untuk penelitian Pertanian Edisi Kedua Penerjemah: Endang Syamsudin dan Justika S. Baharsyah. UI Press. Jakarta.

[4] Habibi, Z., H. Satriawan dan Agusni. 2017. Pengaruh Dosis Pupuk Kompos terhadap Pertumbuhan Tanaman Sawi (Brassica rapa). Agrotropika Hayati. Vol. 4 (4): 305 - 313

[5] Indrayati, L. 2005. Pengolahan Jerami Padi pada Pertanaman Padi Lahan Pasang Surut Sulfat Masam. Abstrak Hasil Penelitian Pertanian Indonesia Pusat Perpustakaan dan Penyebaran Hasil Penelitian Indonesia. Vol. XII No.2. Bogor.

[6] Kresnatita, S., Koesriharti dan Santoso, M. 2013. Pengaruh Rabuk Organik terhadap Pertumbuhan dan Hasil Tanaman Jagung Manis. Indonesian Green Tachnology. Vol. 2 (1): $8-17$

[7] Lakitan, B. 1995. Hortikultura I. Teori Budi Daya dan Pasca Panen. Raja Grafindo Persada. Jakarta.

[8] Mahmudi, S., H. Rianto dan Historiawati. 2017. Pegaruh Mulsa Plastik Hitam Perak dan Jarak Tanam pada Hasil bawang Merah (Allium cepa fa. ascalonicum, L.) varietas Biru Lancor. Vigor. Jurnal Ilmu Pertanian Tropika dan Subtropika. Vol. 2 (2): 60 - 62

[9] Maruli, Ernita dan Gultom, H. 2012. Pengaruh Pemberian NPK Grower dan Kompos terhadap Pertumbuhan dan Produksi Tanaman Cabai Rawit (Capsicum frustencen L.). Dinamika Pertanian. Vol 27 (3): 149 155

[10] Muslim, M. Dan R. Soelistyono. 2017. Pengaruh Penggunaan Mulsa Plastik Hitam Perak dengan Berbagai Bentuk dan Tinggi Bedengan pada Pertumbuhan Tanaman Kubis Bunga (Brassica oleracea var. Botrytis L.) Plantopica. Vol. 2 (2): 85 - 90

[11] Raksun, A. dan Mertha, I.G. 2018. Pengaruh Kompos Terhadap Hasil Panen Tomat (Lycopersicum esculentum Mill). Pijar MIPA. Vol. 13 (1): 56 - 59

[12] Raksun, A. L. japa dan I.G. Mertha. 2018. Pengaruh Kompos Kotoran Kuda Terhadap Pertumbuhan Kacang Panjang. Biologi Tropis. Vol. 18 (2): 170 - 173

[13] Syafriliandi, Murniati dan Idwar. 2016. Pengaruh Jenis Kompos terhadap Pertumbuhan dan Produksi Tanaman Jagung Manis. JOM Faperta. Vol 3 (2) p. 1 - 9

[14] Noverita, S.V. 2005. Pengaruh Pemberian Nitrogen dan Kompos Terhadap Komponen Pertumbuhan Tanaman Lidah Buaya (Aloe vera). Jurnal Penelitian Bidang Ilmu Pertanian. Vol. 3 (3): $95-10$. 